This item was submitted to Loughborough's Research Repository by the author.

Items in Figshare are protected by copyright, with all rights reserved, unless otherwise indicated.

\title{
Printability of elastomer latex for additive manufacturing or 3D printing
}

PLEASE CITE THE PUBLISHED VERSION

http://dx.doi.org/10.1002/app.42931

\section{PUBLISHER}

(C) Wiley Periodicals, Inc

\section{VERSION}

VoR (Version of Record)

\section{PUBLISHER STATEMENT}

This work is made available according to the conditions of the Creative Commons Attribution-NonCommercialNoDerivatives 4.0 International (CC BY-NC-ND 4.0) licence. Full details of this licence are available at: https://creativecommons.org/licenses/by-nc-nd/4.0/

\section{LICENCE}

CC BY-NC-ND 4.0

\section{REPOSITORY RECORD}

Lukic, Maria, Jane Clarke, Christopher Tuck, William Whittow, and Garry Wells. 2016. "Printability of Elastomer Latex for Additive Manufacturing or 3D Printing”. figshare. https://hdl.handle.net/2134/21163. 
Final author version:

M. Lukic, J. Clarke, C. Tuck, W. Whittow, and G. Wells, "Printability of Elastomer Latex for Additive Manufacturing or 3D Printing," J. Appl. Polym. Sci., vol. 133, no. 4, pp. 1-7, 2016.

Printability of Elastomer Latex for Additive Manufacturing

Maria Lukic $^{a}$, Jane Clarke ${ }^{\mathrm{a}}$, Christopher Tuck $^{\mathrm{b}}$, William Whittow $^{\mathrm{a}}$ and Garry Wells ${ }^{\mathrm{c}}$

a'Loughborough University, Loughborough LE11 3TU, Leicestershire, UK

M.lukic@lboro.ac.uk, J.Clarke@lboro.ac.uk, W.G.Whittow@lboro.ac.uk

${ }^{\mathrm{b}}$ Nottingham University, University Park, Nottingham, NG7 2RD, UK

Christopher.Tuck@nottingham.ac.uk,

'Defence Science and Technology Laboratory, Porton Down, Salisbury, Wiltshire, SP4 0JQ, UK GMWELLS@dstl.gov.uk

* Corresponding author. Tel: +44 1509223154 


\section{Abstract}

$3 \mathrm{D}$ printing is a new, rapidly developing technology which has the potential to revolutionise fabrication of certain high value, complex products. Until now conventional elastomers have not been widely used in the additive manufacturing process and so experiments have been carried out to determine the feasibility of additive manufacturing using ink jet printing of elastomeric latex materials. Particle size, viscosity and surface tension were measured for 5 latex materials and the XSBR latex was predicted as the one most likely to be printable. Printing trials carried out with the XSBR as the ink proved it to be printable, although technical problems of agglomeration and print head clogging need to be addressed and both the material and process need to be optimised for consistent printing to be achieved. Printing trials were also carried out using a conductive silver ink on a cast latex substrate. Although sintering of the ink film was successful and the film adhered to the elastomer, cracking of the conductive ink film meant that electrical conductivity was not achieved. Therefore, it was concluded that a more flexible ink will be required for elastomer based flexible electronic applications. 


\section{INTRODUCTION}

Additive manufacturing, sometimes referred to as 3D printing, is the fabrication of an object by progressive addition of layers of material. Within each layer the material is either laid down or solidified in lines or strips, in much the same way that a 2D image is printed. Hence, additive manufacturing machines include a means of depositing or solidifying material and a means of scanning in $\mathrm{X}, \mathrm{Y}$ and $\mathrm{Z}$ directions to control the positioning of the material. There are many different additive manufacturing technologies available, usually classified according to the means by which the materials is deposited or solidified.

Since its advent in the 1980 's, rapid prototyping has developed into a broader and more capable technology referred to as additive manufacturing. Technology development is currently expanding rapidly, as its potential to produce highly complex and custom-made products is recognised. However, the main disadvantages of additive manufacturing are the limited range of materials that can be processed in this way and the fact that the material properties are often inferior to those used in more conventional fabrication methods. Rubbers or elastomers are one of the classes of materials particularly underprovided for in the additive manufacturing industry. A brief review of the current additive manufacturing technologies relevant to rubber-like materials is given below.

Elastomers can be divided into two groups: firstly the conventional cross-linked or thermoset elastomers, and secondly the thermoplastic elastomers (TPEs). For the TPEs the techniques that are available for use with thermoplastics can be applied. One of the earlier methods to be developed is selective laser sintering (SLS). In SLS the object is built up within 
a bed of powdered material by selectively sintering or melting the thermoplastic powder with a laser. For each layer the bed is moved down a step and a layer of fresh powder is spread over the whole bed, including the partly formed object. The laser is then used to melt the next layer onto the object, fusing it to the already completed object. Published work in this area shows that there are very few TPEs commercially available for SLS and those that are available generally have inferior mechanical properties to those materials available for conventional processing, such as injection moulding and extrusion ${ }^{1-5}$. Another technology which can be applied to TPEs is fused filament deposition modelling. In recent years this technology has been taken up by many machinery manufacturers and it has become the cheapest form of 3D printer, even affordable to have in schools and at home. The material is supplied as a filament and is fed into a heated extruder head from which it is deposited, solidifying on cooling. There are commercially available TPEs in filament form but very little published research in this area ${ }^{6}$. There is clearly scope for further research into TPEs, however, the development of thermoset elastomers for additive manufacturing is even more challenging.

There are currently two main types of thermoset elastomeric materials compatible with additive manufacturing technology, one is liquid silicone rubber and the other is a set of UV curable materials, including polyurethane and acrylic based polymers. The liquid silicone elastomers can be processed using an extrusion process, sometimes referred to as direct writing. The material is deposited from a micro-dispensing device or syringe. The high viscosity of the material is largely relied upon to maintain the shape of the product, while most of the cross linking reaction can be carried out as a separate process after forming. This technique has been used to make a product with a controlled porosity and indicates it 
may have a niche application for silicone elastomer materials ${ }^{7}$. However, this form of direct extrusion is not suitable for the vast majority of elastomers which can be classed as soft solids and have much too high a viscosity to be extruded in this way. There are two ways in which UV curable polymers can be additively manufactured. The first is stereolithography, in which the object is built up in a batch of liquid polymer which is selectively cured, as the object is lowered step-wise into the bath as each layer is cured. In the second method the liquid polymer is printed by an inkjet process and is cured after deposition by a UV light attached to the print head ${ }^{8-11}$. This combination of UV curable polymer and inkjet printing technology is potentially very powerful, allowing a range of materials to be printed at the same time to a high level of precision. However, although rubber-like materials with a range of hardness are commercially available, their mechanical properties fall well below those of most conventional rubber compounds.

In summary, it is clear that additive manufacturing of elastomers is currently extremely limited from a material point of view because only three classes of rubbery materials (TPE, liquid rubbers, photo-curable polymers) are compatible with the technology. The types of elastomer with the required performance for most automotive, aerospace, construction and engineering applications cannot be used in additive manufacturing processes at the moment.

This paper reports an investigation into an alternative approach to additive manufacturing of elastomeric materials; inkjet printing of latex, a suspension of nano-scale elastomer particles in water. Taking this approach, a range of conventional elastomers becomes available, with a winning combination of high molecular weight and low viscosity. The high 
molecular weight leads to good mechanical properties, while the low viscosity means the latex is potentially inkjet printable.

If it proves possible to print with latex, there follows an opportunity to create elastomeric composites with a controlled distribution of filler, leading to novel properties being developed that would be unobtainable by any other means. An application where this may be particularly useful is components which also incorporate electromagnetic interference (EMI) and radio frequency interference (RFI) shielding. However, there are many interesting mechanical performance characteristics that could also be obtained be controlling the distribution of filler and hence local stiffness and strength of a product.

To determine whether elastomer latex is potentially inkjet printable it is necessary to consider the inkjet process and the required properties of the ink. In most inkjet printing techniques an electric field applied to a piezoelectric print head causes the piezoelectric plates within to oscillate and eject the ink. There are many properties of the ink that affect the printing process, such as the viscosity, density, $\mathrm{pH}$, particle sizes, and surface tension. The ideal viscosity for jetting ink is $20 \mathrm{cp}$ with an ideal surface tension of approximately 40 $\mathrm{mN} \cdot \mathrm{m}^{-1} 12$. These properties have been brought together by Fromm into a dimensionless number, $Z$, which predicts printability of the ink if the value of $Z$ is larger than two. ${ }^{13}$ Fromm's equation, which also provides the Ohnesorge number, is given in Equation 1 below.

$$
Z=\frac{(d \rho \gamma)^{\frac{1}{2}}}{\eta}=O h^{-1}
$$

Where $\eta$-viscosity, 


$$
\begin{aligned}
& \rho \text {-density } \\
& \gamma \text {-surface tension of the liquid } \\
& d \text {-diameter of the nozzle aperture } \\
& O h \text { - Ohnesorge number }
\end{aligned}
$$

The formula was used in the research reported in this paper to determine the potential printability of 5 elastomer latex materials, using viscosity, density and surface tension of the liquid latexes. Particle sizes of the latexes were also measured because it is necessary that they should be small enough to pass through the print head without blocking. In 3D printing the printed material forms the base for the following layer and so its properties as a substrate are important, for example, its wetting behaviour with the ink. For this reason, the surface energy of the dried latex material was also measured. Printing trials were carried out using latex as the ink. With a view to possible application in flexible electronics, printing trials were also carried out using silver ink on dried latex sheets, to determine whether a conductive layer could be maintained on an elastomeric substrate.

\section{EXPERIMENTAL}

\section{Materials}

The five liquid latex materials were supplied by Synthomer (Synthomer Deutschland GmbH, Werrastraße 10, 45768 Marl, Germany). The elastomer type, abbreviation and trade names are given in Table 1. The silver ink used was a conductive silver ink, supplied by Advanced Nano Products (ANP Co., Ltd., 78 Geumhoangol-gil, Bugang-myeon, Sejong, Korea). 


\section{Viscosity}

To determine the viscosities of the liquid latex, a Brookfield viscometer was used with Spindle 2 and a speed of $50 \mathrm{rpm}$. A Malvern Kinexus Pro rheometer was also used to determine the shear viscosity of the latex at a range of strain rates. The viscosities were measured at strain rates from $10 \mathrm{~s}^{-1}$ to $500 \mathrm{~s}^{-1}$ at a temperature of $24.5^{\circ} \mathrm{C}$.

\section{Surface tension of the liquid latex}

The surface tension measurements were carried out using a Kruss KSB Instruments Contact Angle Goniometer. Using the pendant drop method on the contact angle equipment it was possible to measure the surface tension of each latex material by ejecting small quantities of latex through a needle and measuring the drop dimensions with the aid of a camera and image analysis software.

\section{Particle size}

A Malvern Mastersizer 2000 was used to determine particle size of the liquid latex materials by laser light scattering. A few drops of liquid latex were dispersed in de-ionized water and sonicated at $3000 \mathrm{~Hz}$ for $60 \mathrm{~s}$ to disperse any particles that may have agglomerated. The equipment provided average particle sizes and particle size distributions. 


\section{Latex sheet preparation}

Cast latex sheets were prepared so that their properties and behaviour as a printing substrate could be determined. For each latex sample, approximately $4 \mathrm{~g}$ of latex was poured into a $5 \mathrm{~cm}$ diameter petri dish. A lab oven with fan was used to dry the latex materials at $70^{\circ} \mathrm{C}$. The samples were placed onto a metal tray to ensure that the samples were level in order to obtain a uniform thickness of the latex once dried. At 15 minute intervals the samples were removed from the oven and weighed until constant weight had been achieved. The maximum total drying time was 1 hour 45 minutes for each sample measured. The final result provided $2 \mathrm{~mm}$ thick sample materials that were used to determine surface energy. Sheets of dried CIBR and XSBR latex were also used as the substrate for silver ink printing trials.

\section{Surface energy of the latex sheets}

The sessile drop contact angle method was used to measure the surface energy of the latex sheets using a Kruss KSB Instruments Contact Angle Goniometer. De-ionized water and diiodemethane were used for the measurements. Once the drop touched the surface an image was captured and with the aid of the software on the Dataphysics equipment the contact angle was calculated.

\section{Printing trials: Conductive silver ink onto latex sheets}

A Dimatix Materials Printer DMP-2800 was used for all the printing trials. Trials were conducted to print conductive silver ink onto the cast latex sheets in order to determine the 
suitability of dried latex as a substrate for printing. CIBR and XSBR latex sheets were used for these trials as they had suitably smooth and flat surfaces. A section of the material was chosen where a straight $5 \mathrm{~cm}$ long and $2 \mathrm{~mm}$ wide line could be printed. Two layers of conductive silver ink were printed onto the surface of the latex. It was not required to let the silver ink dry before printing a second layer as during the printing process the temperature in the nozzle reached approximately $55^{\circ} \mathrm{C}$, enough to evaporate the solution in which the silver particles were dispersed. After the printing process the silver ink was sintered on a hot plate between $125^{\circ} \mathrm{C}$ and $130^{\circ} \mathrm{C}$. Sintering these particles was required if a circuit that could carry a current was to be formed. Once the ink had been exposed to this temperature for approximately 3 to 4 minutes for each latex sheet, it was found that the latex material had begun to deform under the high temperatures. It was taken off the hot plate and allowed to cool for a few seconds. Using a multimeter, it was found that the silver circuit could not carry a current. Examination of the printed silver using SEM revealed a very cracked surface. It was thought that this might be due to poor sintering of the ink and a further printing trial was carried out, followed by different sintering conditions. However, in the second printing trial in which sintering was carried out at $90^{\circ} \mathrm{C}$ for 8 hours in a laboratory oven, the ink layer still showed cracks.

\section{Printing trials: Printing with liquid latex as an ink}

A diluted sample of XSBR containing $35 \%$ solids content combined with $1 \%$ concentration by weight of Triton surfactant was passed through a 5 micron filter, to prevent any particle agglomerates from blocking the nozzles, prior to filling a $2 \mathrm{ml}$ cartridge. The settings for printing were a maximum jetting frequency of $20 \mathrm{kHz}$ and jetting voltage of $26 \mathrm{~V}$ calibrated 
for each nozzle. A silicone coated paper was used as the substrate for the latex. The area for printing was selected on the computer using the camera attached to the printer and the dimensions of a $2 \times 2 \mathrm{~cm}$ square were set to print.

Cleaning cycles were set during the printing process for every ten passes the printer made over the substrate, to prevent any latex ink that may have leaked out from drying and blocking the nozzles on the printer head. It was not essential to wait for the latex ink to dry before printing on additional layers.

\section{Thickness and morphology of printed layers}

Samples of latex from the printing trials were examined using scanning electron microscopy (SEM) to observe their morphology. All the samples were sputter coated with silver. A Carl Zeiss (Leo) high resolution field emission gun scanning electron microscope (FEGSEM) model 1530VP was used with 10 to $12 \mathrm{~mm}$ working distance, EHT (extra high tension) of 5kV and a standard aperture size of $30 \mu \mathrm{m}$.

An InfiniteFocus Alicona benchtop optical 3-D surface measurement and characterisation system was used to measure the thickness of the printed XSBR latex. The Alicona uses a small depth of focus optical system with vertical scanning to provide an area analysis. A 10 $\mathrm{nm}$ vertical resolution and $2.5 \mathrm{~mm} . \mathrm{s}^{-1}$ scan speed was used to determine sample thickness. 


\section{RESULTS AND DISCUSSION}

\section{Viscosities of the liquid latex}

Viscosities for all latex samples found using the Brookfield viscometer are shown in Table 2. The viscosities measured over a range of strain rates are displayed in Figure 1 on logarithmic scale, the negative slope showing shear thinning behaviour. Numerical values for viscosity at strain rates of 10 and $500 \mathrm{~s}^{-1}$ are presented in Table 3. Inks with viscosities less than 20 $\mathrm{mN} \cdot \mathrm{m}^{-1}$ are best suited for inkjetting as they will not block the print head nozzles ${ }^{12}$. Therefore, the latex samples with the viscosities best suited for inkjetting are the XNBR, $\mathrm{XSBR}$, and $\mathrm{CIBR}$. However, there is also the possibility of diluting the natural rubber latexes to obtain a lower viscosity.

\section{Surface Tension of the liquid latexes}

Surface tension values of the latexes are shown in Table 3. The values for surface tension that are most favourable are those of XNBR, CIBR, NR and PVNR latexes as they are lower than $40 \mathrm{mN} \cdot \mathrm{m}^{-1}$. A surface tension higher than $40 \mathrm{mN} \cdot \mathrm{m}^{-1}$ can prevent the ink from jetting properly, and a surface tension that is too low could result in the ink leaking out of the print head.

\section{Surface Energy of the Cast Latex Sheets}

The surface energy values of the cast latex samples are displayed in Table 2 . The surface energies of the cast sheets of XNBR and ClBR are significantly higher than the XSBR and NR materials. A high surface energy of a material means that it is more receptive to surface wettability. This characteristic could be detrimental when printing other liquid substances 
that have high water content onto these materials as the droplets will not retain their shape and will want to merge with other droplets, resulting in compromised control of the entire printing process and a low resolution of the printed material.

\section{Particle size}

To prevent clogging of the print head nozzle and enable consistent ejection of the ink, it is generally considered that the particle size for materials in ink should be less than $10 \%$ of the nozzle diameter, $5 \mu \mathrm{m}$ in this case. The particle size results for all five liquid latex materials are presented in Table 3.

Figure 2 shows the particle size distributions for XSBR latex before and after sonication. Before sonication there is a bimodal distribution of particle sizes, the larger particle size peak indicating that agglomeration of the particles has occurred. After sonication a single peak is observed at sub-micrometre size, indicating that the XSBR latex is compatible with inkjet printing, at least with respect to particle size and after sonication.

These results show that sonication can be a pragmatic solution to agglomeration. If the samples that are to be used for printing are exposed to medium intensity bursts of ultrasound with a sonication probe for a period between 60 and $120 \mathrm{~s}$, then the agglomerated particles can be separated and the material will be ready to be inserted into the ink cartridge.

\section{Latex sheet preparation}

The behaviour of the drying latex was a factor that depended purely on the temperature to which the materials were exposed. For the drying behaviour of the liquid materials, there 
were two types of tests that were carried out: one was to create a relatively thick cast latex sheet (approximately 1 to $3 \mathrm{~mm}$ thick) in one go, and the second was to build up a sheet from very thin layers to determine how the material structure will be affected overall as well as to determine if the drying durations change.

The most effective drying temperature for the latex materials was found to be $70{ }^{\circ} \mathrm{C}$. Higher temperatures between $80^{\circ} \mathrm{C}$ and $90^{\circ} \mathrm{C}$ resulted in the formation of cavities within the dried cast latex due to the formation of bubbles as the aqueous solutions in the material were close to boiling temperatures. These high temperatures also resulted in cracks forming on the surface of the latex, which created materials that have a grainy surface texture for the CIBR, and a leathery surface texture for the XNBR. However, temperatures below $70^{\circ} \mathrm{C}$ resulted in the liquid materials drying at a significantly slower rate.

It was observed during the drying process of the thicker sheets of latex that the material would form a thin film on the top surface. The liquid on the bottom did not have the opportunity to dry at the same rate as the liquid near the surface due to the relative permeability of the dried latex film on the surface. It also caused voids to form around the edges of the materials as the gas from the evaporating liquids would become trapped under the surface film. The material that exhibited these drying properties the most was the XNBR. In some tests, which ran over a period of 6 hours, the bottom surface of the XNBR was still not entirely dry and some residual liquid material was still present.

Overall, the materials that showed the best drying behaviour were the CIBR and the XSBR. 


\section{Printing trials with silver ink}

The first printing trials that were carried out involved printing silver conductive ink onto a cast sheet of latex. The samples that were used to print the ink onto were the XNBR and CIBR. The printed layer of conductive ink was found not to be electrically conducting, due to cracking of the layer. SEM imaging was performed to observe the nature of the cracks in the ink. Figures 3 and 4 display the complex cracks that have formed in the ink. If the surface energies of the ink and substrate are too dissimilar, then the ink can crack and delaminate from the substrate. In Figure 4, secondary cracks running from the main crack are discernible, but delamination of the ink from the surface is not observed. This suggests that the reason for the silver ink cracking was not due to surface energy incompatibility with the ink, but more likely due to differential contraction of ink film and substrate, or to bending stresses during sample handling, causing the ink on the surface to experience tension. The results suggest that a more flexible ink must be used if electrical conductivity is to be achieved, for example, in a flexible electronic application.

\section{Printing with liquid latex as the ink}

Measured surface tension and viscosity values are shown in Table 3, together with the values for printability, Z, calculated from Equation 1. Density of all the latexes was assumed to be $1000 \mathrm{~kg} \cdot \mathrm{m}^{-3}$. The latexes showed some shear thinning behaviour so two values of $Z$ were calculated, one using the viscosity measured at a low strain rate $\left(10 \mathrm{~s}^{-1}\right)$ and the other using the viscosity measured at a high strain rate $\left(500 \mathrm{~s}^{-1}\right)$. 
Only XNBR had a Z value above 1 for both low and high strain rates, but at the higher strain rate, the values of $Z$ are greater than 1 for all the latexes. The printability will therefore depend on the strain rate experienced by the latex during printing. XNBR and XSBR latex samples having the higher $Z$ values would appear to be potentially the best latexes for printing. The XNBR cannot be used because of the large particle sizes and so the XSBR latex was selected to carry out printing trials.

The first printing trial was unsuccessful because, although the latex was ejected from the head, the nozzle became blocked. Considering that the solids content of about $50 \%$ for the XSBR was rather high for printing, most inks having solids contents of the order of $10 \%$, a trial was carried out diluting the latex to a solids content of $35 \%$. It was thought that the reduction in solids content would also reduce the viscosity of the ink, increasing the $Z$ value to a potentially more favourable level. In addition, Triton X-100, a non-ionic surfactant, was added at $1 \%$ to reduce the risk of agglomeration. In the trial with the diluted latex, a $2 \mathrm{~cm}$ square was printed onto a silicone treated paper substrate. An SEM image of the surface of the printed latex is displayed in Figure 5. The lower half of the image shows the printed rubber, while the upper half shows the substrate. The edge of the printed rubber layer, perpendicular to the printing direction, is not perfectly straight, varying by approximately $\pm 50 \mu \mathrm{m}$. There are also some satellite drops visible on the substrate, where some of the drops have broken up during printing. Although this may not indicate a high resolution in terms of conventional printing, for a first attempt, the results look promising. With optimisation of the latex material and the printing process itself it is expected that a good control of dimensions in a manufactured product could be achieved. Ten layers were printed successfully, although there was a slight problem with latex leaking from the printer 
head which meant that frequent cleaning cycles were required during printing. A thickness measurement taken on the InfiniteFocus Alicona equipment, is displayed in Figures 6 and 7. Figure 6 shows the substrate on the left and the printed rubber on the right. The profile below shows a substrate sloping down from left to right and an average thickness of the rubber layer of roughly $18 \mu \mathrm{m}$. Figure 7 shows a thickness map of the area, with the printed rubber on the right. In both Figures 6 and 7 a peak and trough topography is shown corresponding to the lines of printing. Although ideally the surface would be smooth, the fact that the lines are visible does indicate that uncontrolled pooling of the printed latex has not occurred and suggests that with optimisation, a sufficiently good surface topology could be obtained.

The successful printing trial shows the potential for printing with latex, but it is clear that the process needs to be optimised and problems addressed before it can be considered as a viable process for additive manufacturing.

\section{CONCLUSION}

This study has shown that there is a great potential for using liquid latex materials as inks in 3-D printing of elastomers with inkjet technology. Measurement of surface tension and viscosity of the liquid latex, followed by application of the printability equation helped to screen the latex materials for inkjetting compatibility. Measurement of particle size by laser scattering was useful in identifying where agglomeration had occurred and when it had been eliminated by ultrasonic treatment. However, the printing trials showed that the latex ink composition may still need to be adapted for printing to be successful, for example by dilution of the latex and addition of surfactants. The results have also shown that a silver 
ink can be successfully printed onto a latex sheet, giving good wettability and adhesion between the two materials. The silver ink layer was found not to be electrically conductive due to micro cracks being formed, either due to differential shrinkage or due to its rigidity when the elastomer sheet was bent. Nonetheless, the good adhesion between the silver and the substrate elastomer supports the idea that a particulate filler can be printed in combination with a latex ink to create a composite structure with controlled distribution of filler. The results reported it this paper show the great potential for 3D printing of elastomeric materials by inkjet printing of latex but many more printing trials need to be carried out in order to establish the real capability of this technique.

\section{ACKNOWLEDGEMENTS}

The authors would like to thank DSTL for funding this project (National PhD Programme).

(C) Crown copyright 2015. Published with the permission of the Defence Science and Technology Laboratory on behalf of the Controller of HMSO. The authors would also like to thank Dr Gareth Simpson and Synthomer Deutschland GmbH for kindly providing free samples of the latex.

\section{REFERENCES}

1. Goodridge, R. D., Tuck, C. J., Hague, R. J. M. Progress in Materials Science 2012, 57(2), 229267.

2. Kruth, J. P., Levy, G., Klocke, F., Childs, T. H. C. CIRP Annals-Manufacturing Technology 2007, 56(2), 730-759.

3. Levy, G. N.; Boehler, P., Martinoni, R., Schindel, R., Schleiss, P. Controlled Local Properties in the Same Part with Sintaflex-A New Elastomer Powder Material for the SLS Process. In Solid Freeform Fabrication Symposium. Austin, TX., 2005

4. Vasquez, M., Cross, J., Hopkinson, N., Haworth, B. Procedia Engineering 2012,34, 325-330. 
5. Seitz, S., van de Crommert, S., Esser, K. K., McAlea, K. Lasers and Optics in Manufacturing III International Society for Optics and Photonics, 1997, September, pp. 106-111.

6. Elkins, K., Nordby, H., Janak, C., Gray, R. W., Bøhn, J. H., Baird, D. G. (1997). Soft elastomers for fused deposition modeling. In Proc. 8th Solid Freeform Fabrication Symposium (pp. 441448).

7. Duoss, E. B., Weisgraber, T. H., Hearon, K., Zhu, C., Small, W., Metz, T. R., Wilson, T. S. ThreeDimensional Printing of Elastomeric, Cellular Architectures with Negative Stiffness. Advanced Functional Materials, 2014.

8. Rossiter, J., Walters, P., Stoimenov, B. Printing 3D dielectric elastomer actuators for soft robotics. In SPIE Smart Structures and Materials + Nondestructive Evaluation and Health Monitoring (2009, March) (pp. 72870H-72870H). International Society for Optics and Photonics.

9. Wang, L., Lau, J., Thomas, E. L., Boyce, M. C. Advanced Materials 2011, 23(13), 1524-1529.

10. Sugavaneswaran, M., Arumaikkannu, G. Materials \& Design, 2014, 54, 779-785.

11. Moore, J. P., Williams, C. B. Fatigue Characterization of 3D Printed Elastomer Material. In International Solid Freeform Fabrication Symposium 2012, pp. 641-655.

12. Brand, O., Fedder, G. K., Hierold, C., \& Tabata, O. In Inkjet-based micromanufacturing, Korvink, J. G., Smith P. J., Shin D. Y., Eds., John Wiley \& Sons, 2012.

13. Fromm, J. E. IBM Journal of Research and Development, 1984, 28(3), 322-333. 


\section{Captions for Figures and Tables:}

Table 1. Liquid latex materials (provided by Synthomer).

Table 2. Properties of the latex materials

Table 3. Properties of the liquid latex related to printability

Figure 1. Log shear rate vs log shear viscosity for the liquid latex materials

Figure 2. Particle size distribution for XSBR latex before sonication (above) and after sonication (below)

Figure 3. An SEM image of a cast latex sheet with printed silver ink focusing on a section of the ink with cracks

Figure 4. A magnification of a section of the printed silver ink to examine the cause of cracking

Figure 5. An SEM image showing the top surface of the printed rubber at the edge of the square.

Figure 6. Captured image from InfiniteFocus Alicona equipment showing a thickness for the printed latex of $18 \mu \mathrm{m}$.

Figure 7. A 3-D of a section of printed latex and substrate 
TABLE 1 Liquid latex materials provided by Synthomer

\begin{tabular}{|c|c|c|}
\hline Trade Names & $\begin{array}{l}\text { Material } \\
\text { Abbreviation }\end{array}$ & Description \\
\hline Lipren $\mathrm{T} \circledast$ & CIBR & $\begin{array}{l}\text { A colloidal dispersion of a poly(2- } \\
\text { Chlorobutadiene). }\end{array}$ \\
\hline Litex T 71S20® & XSBR & $\begin{array}{l}\text { A colloidal dispersion of carboxylated } \\
\text { styrene-butadiene copolymer }\end{array}$ \\
\hline Synthomer X426C® & XNBR & 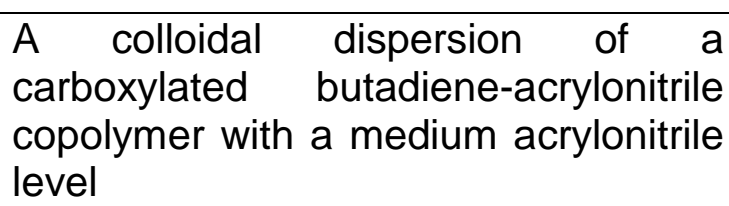 \\
\hline Revultex VRB884® & NR & $\begin{array}{l}\text { A natural rubber latex stabilized and } \\
\text { preserved with ammonia }\end{array}$ \\
\hline Revertex HCE68® & PVNR & $\begin{array}{l}\text { High solids content pre-vulcanized } \\
\text { natural rubber concentrate stabilized } \\
\text { with ammonia and potassium } \\
\text { hydroxide. }\end{array}$ \\
\hline
\end{tabular}

TABLE 2 Some properties of the latex materials

\begin{tabular}{lcccc}
\hline Material & $\begin{array}{c}\text { Surface } \\
\text { energy of the } \\
\text { cast latex } \\
\left(\mathrm{mN} . \mathrm{m}^{-1}\right)\end{array}$ & $\begin{array}{c}\text { Solids } \\
\text { Content } \\
(\text { wt.\%) }\end{array}$ & $\begin{array}{c}\text { Ammonia } \\
\text { Content } \\
(\text { wt.\%) }\end{array}$ & $\begin{array}{c}\text { Brookfield } \\
\text { Viscosity } \\
(\mathrm{mPa} . \mathrm{s})\end{array}$ \\
\hline XNBR & 71.09 & 39 & $\mathrm{n} / \mathrm{a}$ & 4 \\
\hline XSBR & 35.13 & 52 & $\mathrm{n} / \mathrm{a}$ & 12 \\
\hline CIBR & 71.06 & 56 & $\mathrm{n} / \mathrm{a}$ & 12 \\
\hline NR & 39.2 & 60.25 & 0.7 & 120 \\
\hline PVNR & 38.72 & 68.5 & 0.62 & 140 \\
\hline
\end{tabular}


TABLE 3 Properties of the liquid latex related to printability

\begin{tabular}{|c|c|c|c|c|c|c|c|}
\hline \multirow[t]{3}{*}{ Materials } & \multicolumn{2}{|c|}{$\begin{array}{c}\text { Upper decile } \\
\text { particle diameter } \\
(\mu \mathrm{m})\end{array}$} & \multirow{3}{*}{$\begin{array}{l}\text { Surface } \\
\text { Tension } \\
\left(\mathrm{mN} \cdot \mathrm{m}^{-1}\right)\end{array}$} & Viscc & ity Pa.s & \multicolumn{2}{|c|}{ Z } \\
\hline & \multirow{2}{*}{$\begin{array}{l}\text { Before } \\
\text { sonic- } \\
\text { ation }\end{array}$} & \multirow{2}{*}{$\begin{array}{l}\text { After } \\
\text { sonic- } \\
\text { ation }\end{array}$} & & \multicolumn{4}{|c|}{ at strain rates of } \\
\hline & & & & $10 s^{-1}$ & $500 \mathrm{~s}^{-1}$ & $10 s^{-1}$ & $500 \mathrm{~s}^{-1}$ \\
\hline XNBR & 279 & 272 & 29 & 20 & 9 & 1.9 & 4.2 \\
\hline XSBR & 303 & 0.25 & 49 & 106 & 26 & 0.5 & 1.9 \\
\hline CIBR & 138 & 73 & 33 & 117 & 33 & 0.4 & 1.2 \\
\hline NR & 1.6 & 1.6 & 38 & 169 & 45 & 0.3 & 1.0 \\
\hline PVNR & 134 & 124 & 39 & 77 & 40 & 0.6 & 1.1 \\
\hline
\end{tabular}


Figure1

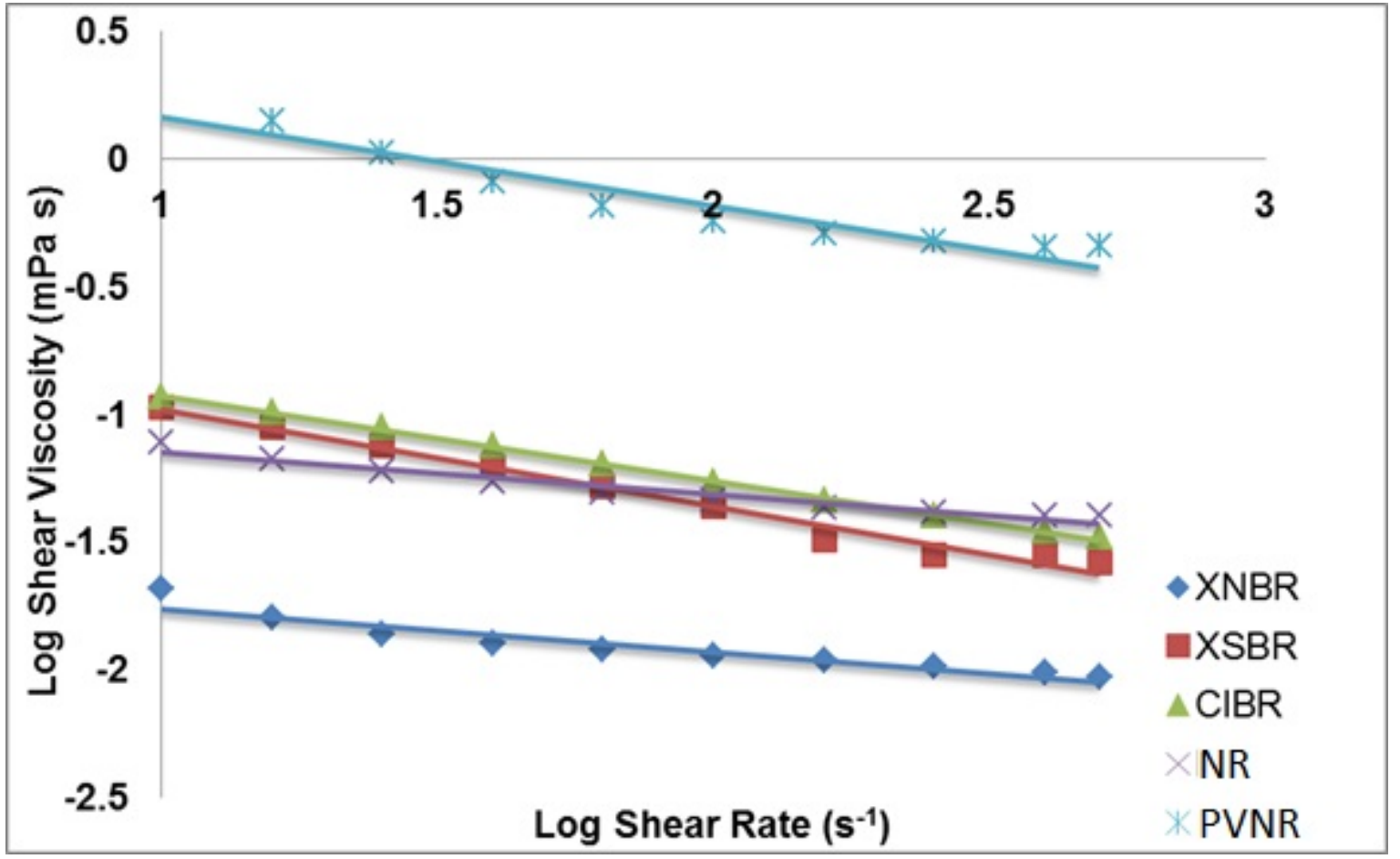


Figure 2

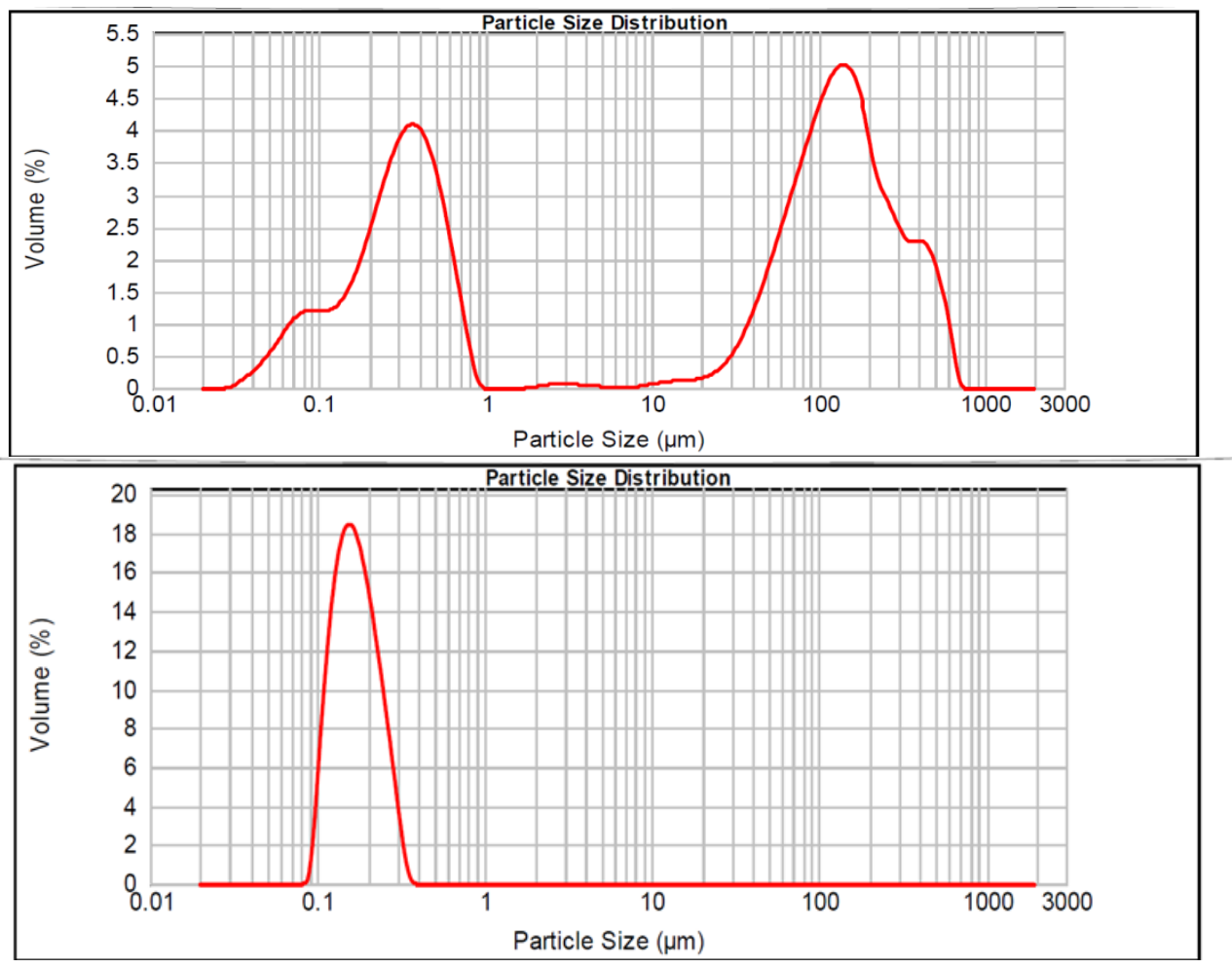


Figure 3

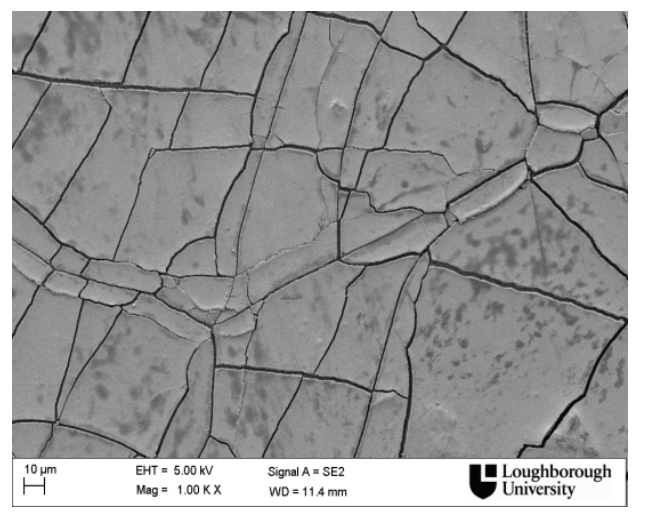

Figure 4

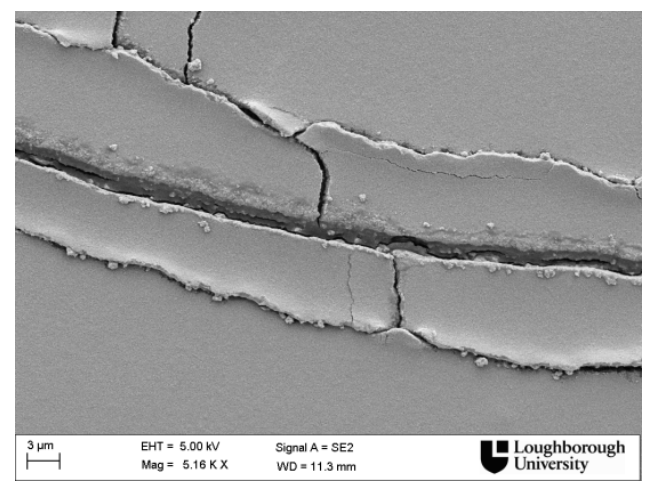


Figure 5

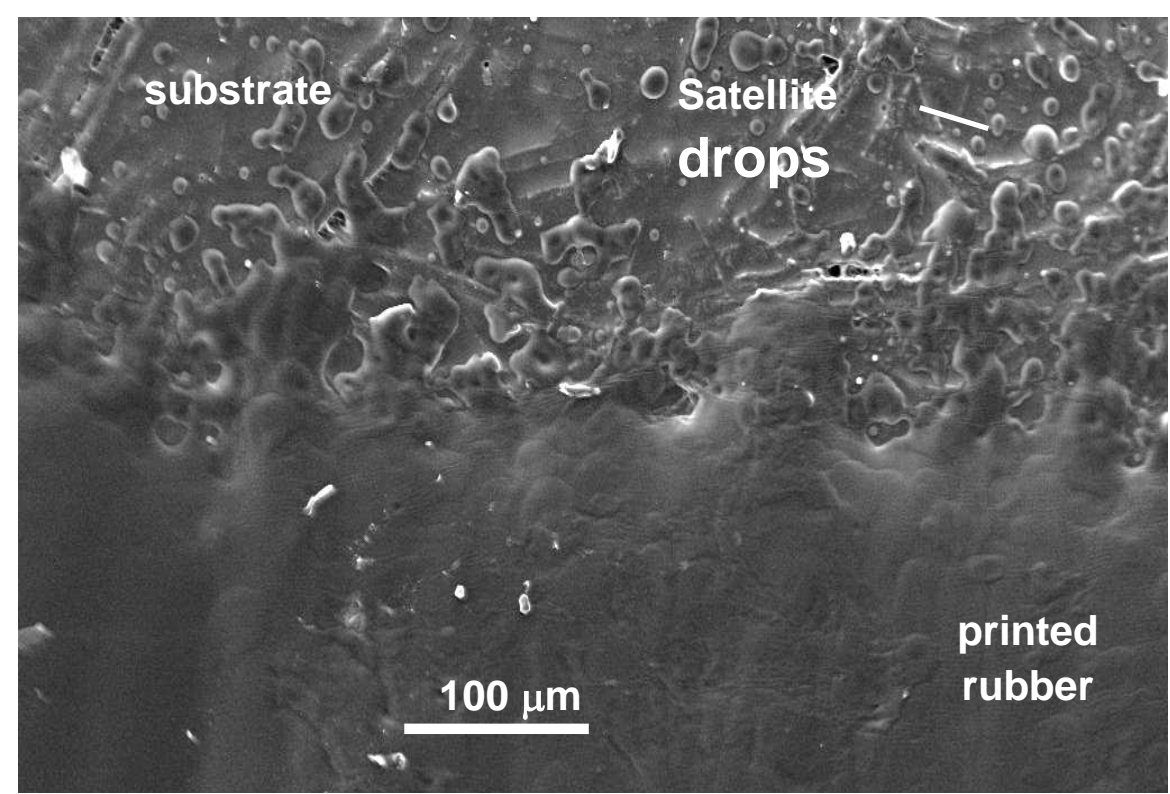


Figure 6

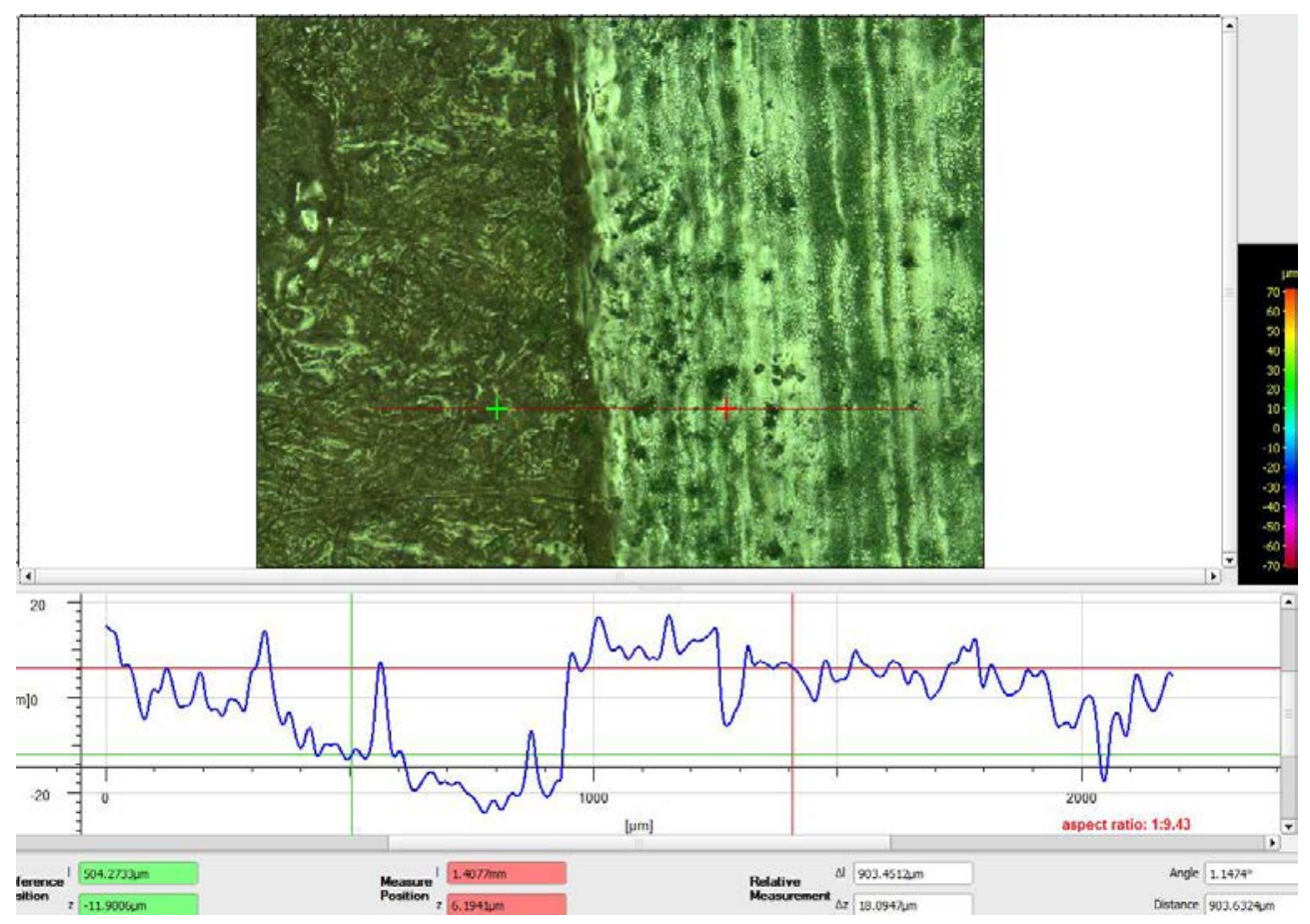

Figure 7

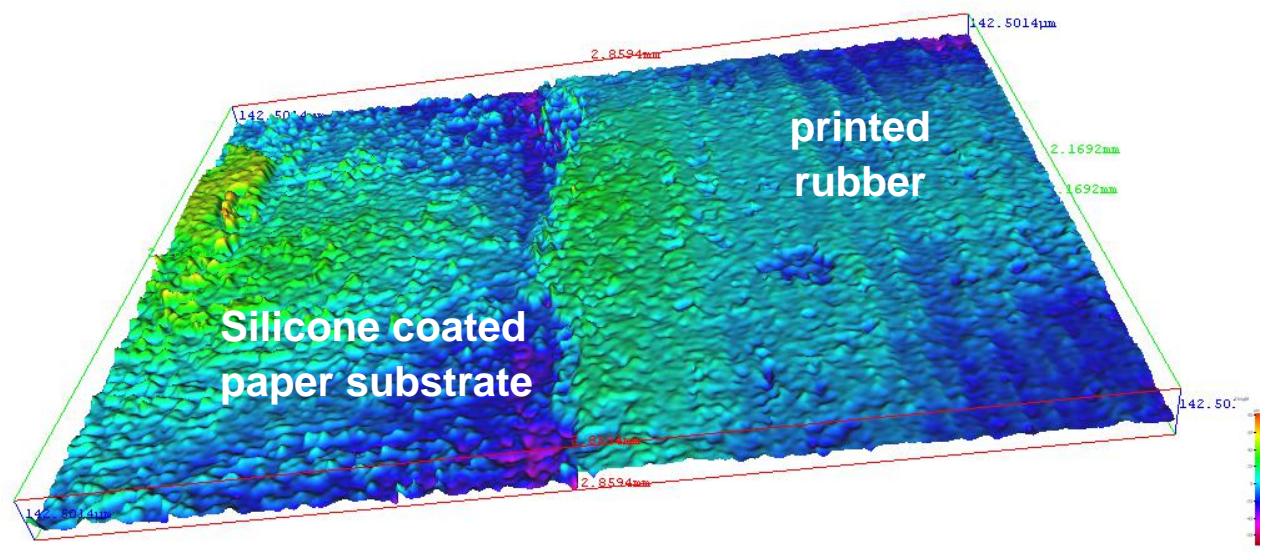

